\title{
GENERATION OF SWITCHING IMPULSE VOLTAGE BY PARAMETERS ADJUSTMENT AND EVALUATING THE WAVE MODULATING INDUCTANCE
}

\author{
Nidhi Chandrakar \\ NIT Raipur, India \\ Department of Electrical Engineering,
}

\author{
Chadaram Chandra Sekhar \\ NIT Warangal, JRF, India, \\ Department of Electrical Engineering,
}

\begin{abstract}
This paper presents an optimization method for the design and analysis of switching impulse generation according to the requirements of the international standard IEC60060-31. To reduce the size of the switching impulse generator the name transformer boosting method has introduced and also to increase its portability and feasibility in field of testing an optimization method has been done for the calculation of the primary side winding of a transformer, to generate target switching impulse, transformer primary side component parameters like equivalent capacitance magnetic inductance, leakage inductance, wave-modulating inductance ( $L)$, load capacitance $(\mathrm{C} 2)$ and winding resistance $(\mathrm{R} 1, \mathrm{R} 2)$ has been found. To calculate the wave-modulating inductance for keeping one parameter variable and remaining all parameters should be kept constant in the circuit and draw the characteristics of the generated waveform to find the best parameter for reducing the inductance effect for the circuit. For that best-reducing inductance need to design any controller is complex. So we need to reduce the higherorder to the lower-order system by using stability equalization method and optimization method. In this paper, a brief introduction is defined by a simple example.
\end{abstract}

Keywords-Switching Impulse, Impulse Generator, Optimization Method, wave-modulating inductance, stability equalization method, controller design.

\section{INTRODUCTION}

Generally, for high voltage types of equipment a frequent failure occurs, to reduce the failures more awareness has been focused on the impulse resist voltage test in the field. For testing the strength of the insulation of electrical equipment in high voltage and also for the voltage testing traditional impulse generator Marx circuit is used [1-2]. Replacing the output waveform time is more in this circuit and this Marx generator is needing a large amount of work about output. This means it needing a large workforce. In this study we used impulse transformer to amplify input impulse voltage, this complete equivalent circuit is analyzed correctly to take control of the output of the generator [1-5]. By just adjusting the circuit parameter an optimization method has been proposed. When inductance is equal to zero, the standard waveform of impulse is observed, and when there is a wave-modulating inductor (L) there is the change in the front time as well as in the overshoot [6].Those changes are needed to consider for a proper design of an impulse generator. Calculation of inductance which is present in the system of an impulse generator, by knowing the output waveform of impulse is attempted. In this study the inductance value changing from zero to some finite value is identified corresponds to the peak overshoot of the impulse output.

\section{PRINCIPLE OF TRANSFORMER BOOSTING- BASED IMPULSE GENERATOR}

There is guidance to design the transformer's primary side winding circuit and also to find the parameters of the circuit which is based on the transformer induction, firstly this section has proposed the fourth-order equivalent circuit to build a switching impulse. Waveform parameters measured with the change in the parameter of the circuit. After that, an optimization method has been made to choose the parameter of the circuit.

\section{A. EQUIVALENT CIRCUIT ANALYSIS}

A magnify impulse voltage is producing at the secondary side of the transformer is by providing a small impulse at the primary side of the transformer as an input to that transformer. This is the basic idea behind generating an impulse from a transformer. A single-phase transformer is used here to generate an impulse voltage it needs to hold out against the impulse voltage which is having a short rise time, therefore, the transformer must have high insulating strength to bear impulse and fight against impulse voltage work condition. This condition is a necessary technical premise to make the output as an impulse voltage without getting fail. 


\section{B. ANALYSIS OF FOURTH ORDER IMPULSE GENERATOR CIRCUIT}

Fourth-order Equivalent Circuit with residual inductance for the Impulse Generator. An equivalent circuit, the circuit parameters are L i.e. wave modulating inductance, $\mathrm{C} 1$ is charging capacitor in the impulse generator circuit, C2 is a load-part capacitor, where R1 and R2 is wave shaping resistor, so overall transfer function for this fourth-order circuit characteristic is the equation shown in (1).

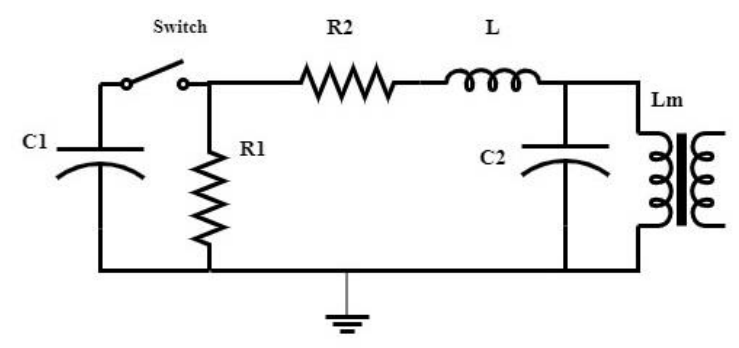

Impulse Generator.

$$
\begin{aligned}
& b=\left(L_{m} C_{1} C_{2} R_{2}+\frac{L L_{m} C_{2}}{R_{1}}\right) \\
& c=\left(L C_{1}+L_{m} C_{1}+L_{m} C_{2}+\frac{L_{m} R_{2} C_{2}}{R_{1}}\right) \\
& d=\left(C_{1} R_{2}+\frac{L}{R_{1}}+\frac{L_{m}}{R_{1}}\right) \\
& e=\left(\frac{R_{1}+R_{2}}{R_{1}}\right) .
\end{aligned}
$$

For example, take values for $\mathrm{C} 1=3 \mathrm{uf}, \mathrm{C} 2=0.22 \mathrm{uF}, \mathrm{Lm}=1.3 \mathrm{H}$, $\mathrm{L}=0 \mathrm{H}, \mathrm{R} 1=2230 \mathrm{ohm}, \mathrm{R} 2=33 \mathrm{ohm}$, and analyzing transfer function and determined the standard responses and their corresponding peak overshoot. It is a simple equivalent diagram to evaluating the parameters of switching impulse voltage to better understanding the performance when switching occurs in the system.

$\left(L L_{m} C_{1} C_{2}\right) \frac{d^{4} i}{d t^{4}}+\left(L_{m} C_{1} C_{2} R_{2}+\frac{L L_{m} C_{2}}{R_{1}}\right) \frac{d^{3} i}{d t^{3}}+\left(L C_{1}+L_{m} C_{1}+L_{m} C_{2}+\frac{L_{m} R_{2} C_{2}}{R_{1}}\right) \frac{d^{2} i}{d t^{2}}+\left(C_{1} R_{2}+\frac{L}{R_{1}}+\frac{L_{m}}{R_{1}}\right) \frac{d i}{d t}+\left(\frac{R_{1}+R_{2}}{R_{1}}\right) i=0$

The following $4^{\text {th }}$ order derivate equation (2) is found shown below

$v_{\text {out }}(S)=\frac{V\left(S^{2} L_{m} C_{1}+S \frac{L_{m}}{R_{1}}\right)}{\left(L L_{m} C_{1} C_{2}\right) S^{4}+\left(L_{m} C_{1} C_{2} R_{2}+\frac{L L_{m} C_{2}}{R_{1}}\right) S^{3}+\left(L C_{1}+L_{m} C_{1}+L_{m} C_{2}+\frac{L_{m} R_{2} C_{2}}{R_{1}}\right) S^{2}+\left(C_{1} R_{2}+\frac{L}{R_{1}}+\frac{L_{m}}{R_{1}}\right) S+\left(\frac{R_{1}+R_{2}}{R_{1}}\right)}$

The following fourth-order derivative equation is obtained when the constants of the terms are replaced with the constants $\mathrm{a}, \mathrm{b}$, and c, respectively [1].

$$
\begin{gathered}
a \frac{d^{4} i}{d t^{4}}+b \frac{d^{3} i}{d t^{3}}+c \frac{d^{2} i}{d t^{2}}+d \frac{d i}{d t}+e i=0 \\
a=\left(L L_{m} C_{1} C_{2}\right)
\end{gathered}
$$

\section{OPTIMIZATION METHOD}

The major parameter of the waveform can be found with numerical computing, through the basic analytical solution of circuit parameter, like peak time value tp, half-peak time value $\mathrm{t} 2$, enveloping line and oscillation frequency $\mathrm{f}$. Now to determine the circuit parameter, now select one parameter that will change and keep all other parameters constant, repeat this step by selecting other parameters as a variable and again keep remaining parameters constant, this step will repeat till the selection of every parameter as a variable. this complete analysis has been done by taking the transfer function of the fourth-order equivalent circuit. By using the poles and zeros concept, here make a transfer 
function with variable $\mathrm{L}$, and the remaining other parameters will be constant. Wave shaping analysis will start by putting $\mathrm{L}=0$, after that finding the response of that circuit, this response will be known as a standard waveform. Now vary any one of the circuit parameters and find the response, and calculate the overshoot. According to that overshoot fix the VP range, to find the inductance value. Repeat this step for all parameters of the circuit, we found that this inductance value is either increasing or decreasing depending on which parameter is varying. With this analysis, we can find which parameter is helpful to reduce the inductance and accordingly overshoot also. In this optimization to calculate all the responses, there should be some range for wave modulating inductance (L). Depending on that range intervals corresponding transfer functions responses will store in data. The form that data the boundary range of $\mathrm{Vp}$ value will select only one peak corresponding that $\mathrm{L}$ value and its maximum peak time will be determined. By using $0.3 \mathrm{Vp}, 0.5 \mathrm{Vp}$, and $0.9 \mathrm{Vp}$ values and their corresponding time will be determined. To understand this optimization an algorithm and flow chart is shown below and one example is taken for analysis.

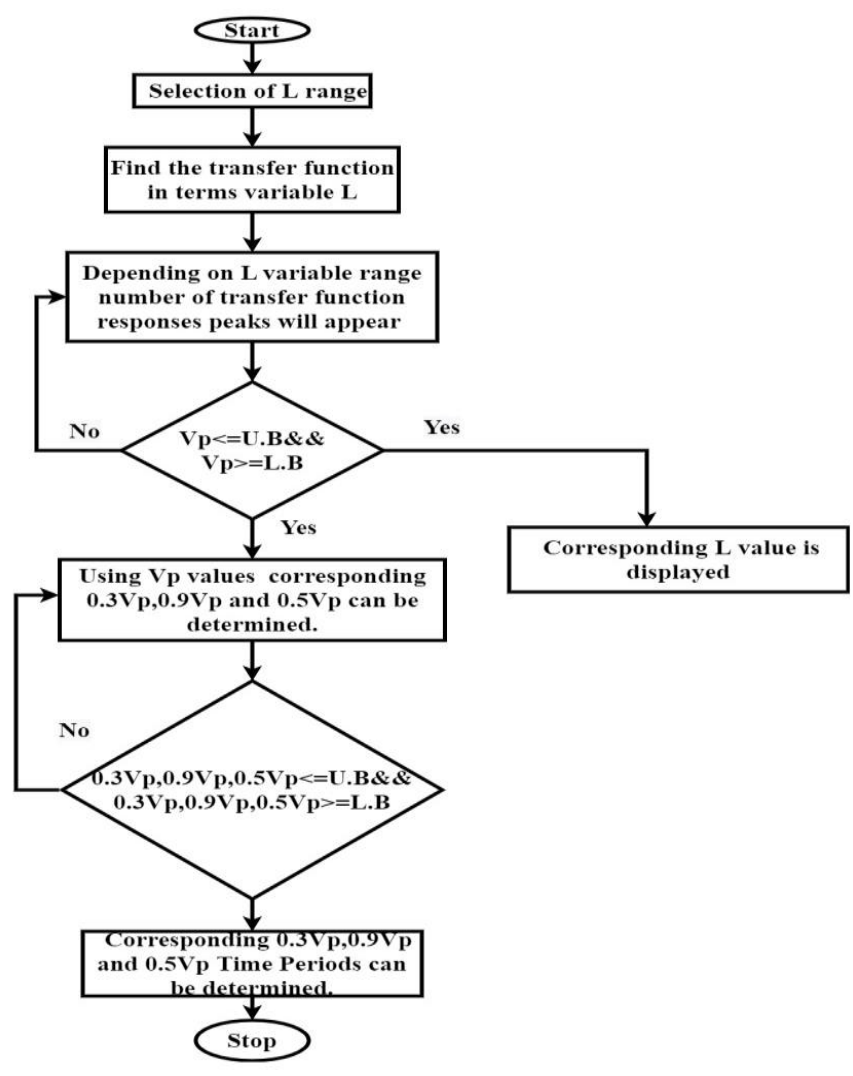

Figure 2: Flow Chart for optimization
According to the IEC standard, the maximum allowable overshoot is $\pm 5 \%$, and if Ls will not be present in the circuit then the standard $\mathrm{Vp}$ is 1 , therefore $5 \%$ of 1 is to be calculated as 0.05 to 1.05 range of boundary values. The program is used to determine the waveform curves and parameters by the known circuit component parameters. Initially, parameters $\mathrm{C} 1, \mathrm{Lm}$, and $\mathrm{R} 1$ are placed to unchanging values that can hardly be adjusted in practice, and the particular parameters of the target waveform, such as tp and $t 2$, are provided. Then, the estimated value ranges for $\mathrm{C} 2$, L, and R2 delimited by a set of parameters such as tp, t2, $\mathrm{t} 3$, t 1 and can be predicted many times by closed computation with the initial value. According to the current value $\mathrm{C} 1, \mathrm{C} 2, \mathrm{R} 1, \mathrm{R} 2, \mathrm{Lm}$ using the waveform parameter calculations to calculate the assembly parameter values $\mathrm{L}, \mathrm{tp}, \mathrm{t} 1, \mathrm{t} 2, \mathrm{t} 3$, f. The appropriate combination of circuit parameter values and the results of $\mathrm{L}$ and $\mathrm{Vp}$ values will show the best parameter variable will reduce peak overshoot and produces less effect due to switching impulse voltages in the system. The program is based on transfer function responses so input voltage is taken as a step. Because of step input, the voltage is 1volt, based on the input voltage the output voltage can be determined. In this S-domain analysis, it is easy to evaluate all the parameter wave shaping and corresponding rise time, peak time, half time, frequency, front time, and tail time.

Code
Step1: Selection of L range
Step 2: Finding transfer function in S
domain with variable L.
Step 3:Getting different peak response
according to L range.
Step 4:Vp<=U.B \& Vp>=L.B.
Step 5 : If no, go to step 4.
Step 6 : If yes, Corresponding Ls value w
display and With Vp value, can find0
.3Vp,0 .9Vp, 0.5Vp
Step 7: 0.3Vp, 0.9Vp,0 .5Vp<=U.B \&
0.3Vp,0.9Vp,0 .5Vp>=L.B.
Step 8: If no, go to step 6.
Step 9: If yes, CorrespondingVpt1, Vpt2,
Vpt3 time value will display.




\section{SIMULATION AND RESULTS}

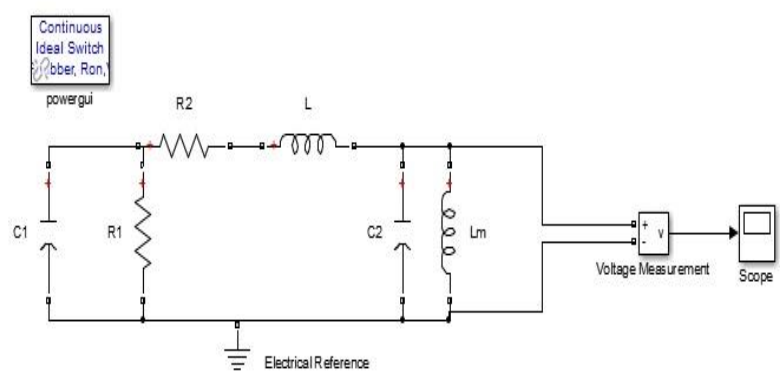

analyze the wave shaping curves and corresponding suitable values to find a better approximation for the $3^{\text {rd }}$ to $4^{\text {th }}$ order circuit [13-14]. Optimization is the better way to understanding the wave shaping parameters to vary according to the desired output response.

In this paper, all the analysis is done in s- domain with transfer function taken the step as an input for easy to find the parameter variations and its corresponding response to switching occur in the system. From the table I to table II, all the parameter variations are similar except $\mathrm{Vp}$ values, according to the peak values the modulating wave inductance is coming into the circuit, because of this inductance oscillation will be increased in the system. To reduce the effect of inductance, there should be an increase or decrease in the one-parameter and kept all the remaining parameters should constant are shown in Table II.

In table II, changing Lm, R1, R2 values the peak values and corresponding $\mathrm{L}$ values are were reduced and in fig 4 the values of the parameters increased R1, R2 value and decreasing $\mathrm{Lm}$ value are given better results, but to reduce transformer inductance is done by using tapping and manual it is very difficult, by increasing $\mathrm{R} 1$ higher value ( $2.22 \mathrm{k} \mathrm{ohm}$ to $22 \mathrm{k} \mathrm{ohm}$ ) then the response is good. If $\mathrm{R} 2$ is changing from $33 \mathrm{ohms}$ to $50 \mathrm{ohm}$ it is giving better results. For this $4^{\text {th }}$ order circuit, the best method to control impulse is by changing R1 value. By varying $c 2$ value inductance is nearly zero but it is not a suitable method to reduce oscillation in the system. Because when $\mathrm{L}=0$ the response is very poor. For that circuit, it is unable to reach a normal peak voltage. After impulse also it will not make any peak value, it doesn't make sense to using to increasing c2 value [14-15].

Calculating $L$ value because during impulse inductance will increases automatically peak value also will increases. Then big oscillation response occurs in the system. To reduce the effects of inductance (L) by changing any good parameter to reduce its peak overshoot. In figure 4 and table II were presented to reduce peak overshoot when impulse occurs. Model order reduction for the original higher-order system to reduced system responses is shown in fig 7 , and the corresponding parameters are shown in table III, by observing the fig,6,7, and Table III original higher-order system response matches with the lower order system response.

In this paper an introduction is given for model order reduction, all the analysis is taken from the reference [20-21], in this numerator coefficients are found by using optimization method [20-21]. And denominator coefficients are found by using the stability equalization method.
In fig 4. clearly shown the response by increasing $\mathrm{C} 1$ from 3 uf to $10 \mathrm{uF}, \mathrm{C} 2$ from $0.22 \mathrm{uF}$ to $1.12 \mathrm{uF} \mathrm{R} 1$ from $2.22 \mathrm{~K}$ ohm to $22 \mathrm{~K}$ ohm, R2 from 33 ohms to 50ohm and Lm decreased from $1.3 \mathrm{uH}$ to $0.5 \mathrm{uH}$ and all the corresponding values are were explained in table 1 . The peak value and parameters are shown in table 1[12]. By using these $\mathrm{Vp}$ values defending a range for finding inductance values corresponding to parameter variations are explained in table 2 and fig 5. The standard response will help to 
Published Online May 2020 in IJEAST (http://www.ijeast.com)

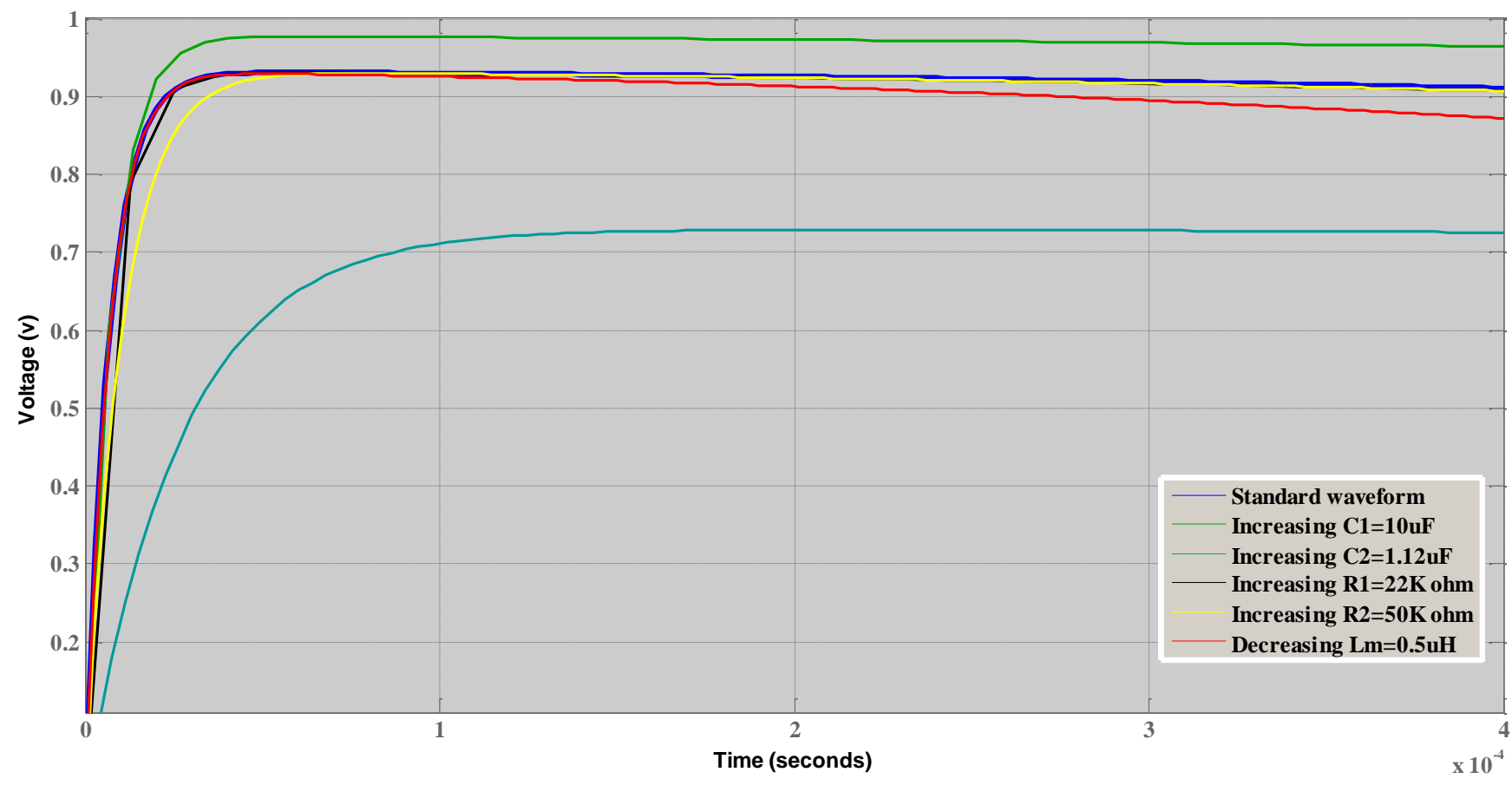

Figure 4: switching impulse voltage waveforms when $\mathrm{L}=0$

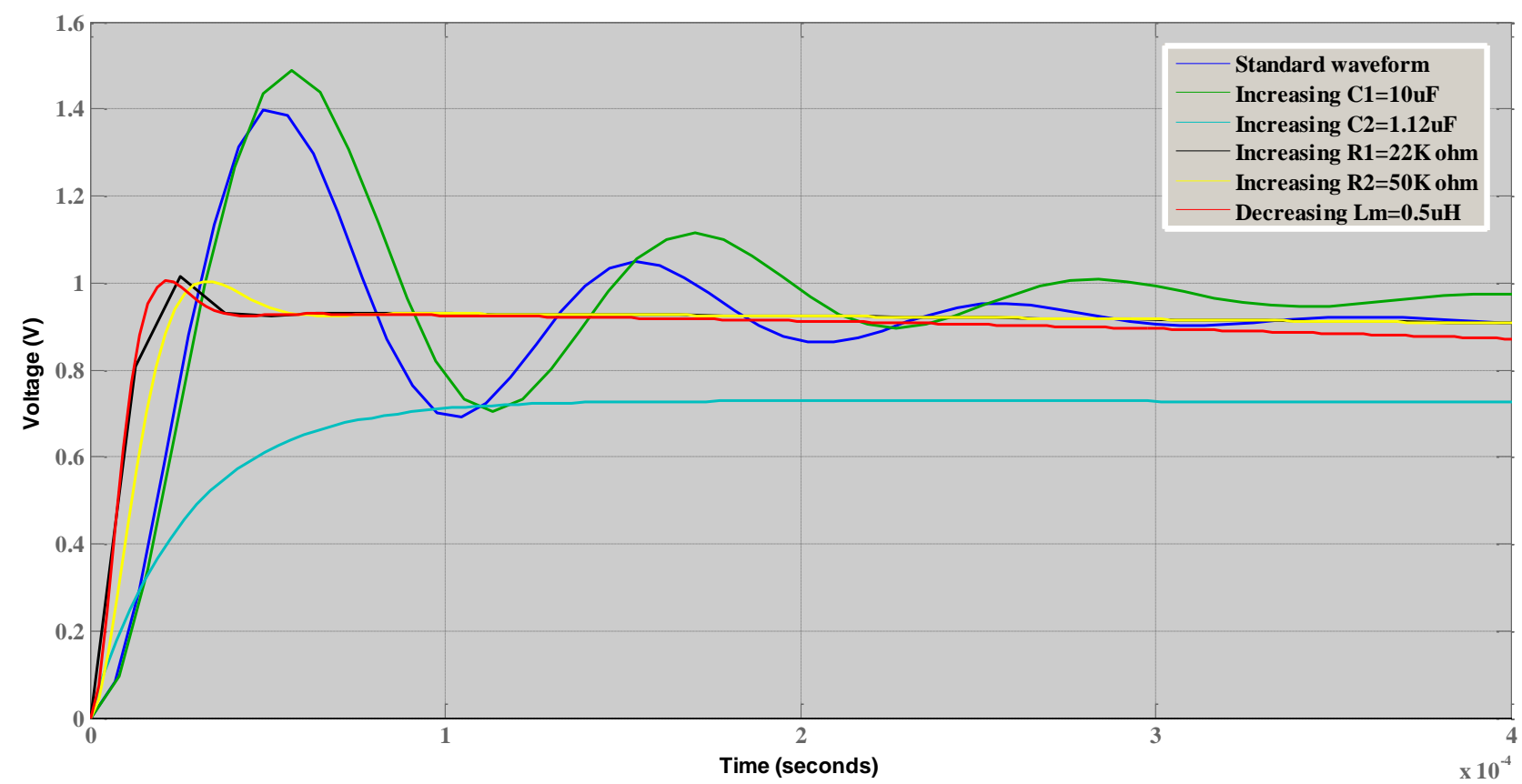

Figure 5: Switching Impulse Voltage Waveforms 
Published Online May 2020 in IJEAST (http://www.ijeast.com)

TABLE II: Switching impulse voltage waveform circuit parameters analysis for $4^{\text {th }}$ order circuit

\begin{tabular}{|c|r|r|r|r|r|r|r|r|r|r|r|r|}
\hline $\mathrm{S.NO}$ & $\begin{array}{r}\mathrm{C} 1 \\
(\mu F)\end{array}$ & $\begin{array}{r}\mathrm{C} 2 \\
(\mu F)\end{array}$ & $\begin{array}{c}\mathrm{R} 1 \\
(K \Omega\end{array}$ & $\begin{array}{c}\mathrm{R} 2 \\
(\Omega)\end{array}$ & $\begin{array}{c}\mathrm{Lm} \\
(\mathrm{H})\end{array}$ & $\begin{array}{c}\mathrm{L} \\
(\mathrm{mH})\end{array}$ & $\begin{array}{c}\mathrm{Vp} \\
(\mathrm{V})\end{array}$ & $\begin{array}{c}\mathrm{tp} \\
(\mu s)\end{array}$ & $\begin{array}{c}\mathrm{t} 1 \\
(\mu s)\end{array}$ & $\begin{array}{c}\mathrm{t} 2 \\
(\mu s)\end{array}$ & $\begin{array}{c}\mathrm{t} 3 \\
(\mu s)\end{array}$ & $\begin{array}{c}\mathrm{f} \\
(\mathrm{kHz})\end{array}$ \\
\hline 1 & 3 & 0.22 & 2.23 & 33 & 1.3 & 1.24 & 1.39 & 48.88 & 2321 & 35.56 & 1534 & 10.22 \\
\hline 2 & 10 & 0.22 & 2.23 & 33 & 1.3 & 1.45 & 1.49 & 56.77 & 3810 & 44.62 & 2427 & 8.807 \\
\hline 3 & 3 & 1.12 & 2.23 & 33 & 1.3 & 0 & 0.72 & 222 & 3265 & 253 & 2736 & 2.252 \\
\hline 4 & 3 & 0.22 & 22 & 33 & 1.3 & 0.16 & 1.015 & 25.47 & 2472 & 229 & 26778 & 19.63 \\
\hline 5 & 3 & 0.22 & 2.23 & 50 & 1.3 & 0.32 & 1.004 & 32 & 2625 & 243 & 2101 & 15.62 \\
\hline 6 & 3 & 0.22 & 2.23 & 33 & 0.5 & 0.14 & 1.004 & 21 & 1578 & 100.7 & 1265 & 23.80 \\
\hline
\end{tabular}

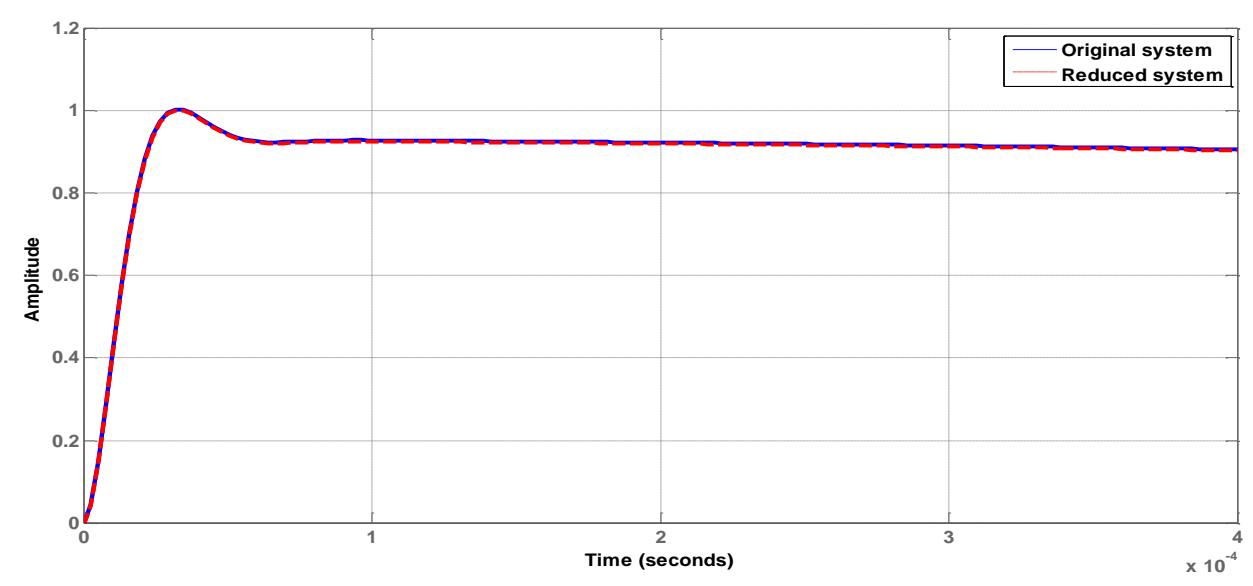

Figure 6 Original and Reduced transfer function response

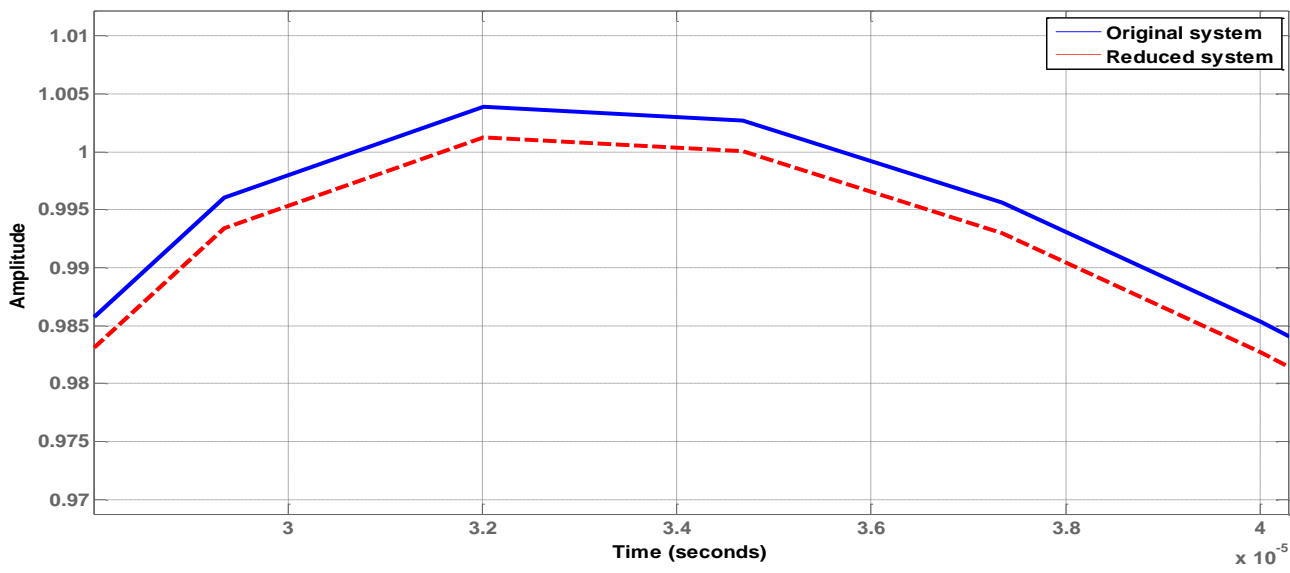

Figure 7 Peak values of Original and Reduced transfer function response. 
An original higher-order system transfer function is given below

$G o(s)=\frac{3.9 e-6 s^{2}+0.000583 s}{2.746 e-13 s^{4}+8.394 e-11 s^{3}+5.152 e-6 s^{2}+0.0008765 s+1.022}$

A reduced lower-order system transfer function

$$
G_{r}(s)=\frac{638 s}{s^{2}+172 s+244565}
$$

Reduced model parameter values are similar to the original higher-order system. Reduced model numerator coefficients are using optimization and denominator coefficients are found by using stability equalization method [18]. In this paper, only results are shown. To design any controller for higher-order systems is difficult, to reduced complexity higher system can be reduced to a lower order system and design a controller for reduced model and implement that controller to the higher-order system. It is one of the ideas to use high voltage applications that can be used by using model order reduction to get simple analysis or to design controlling equipment for high voltage applications based on the response of the reduced model. This paper is explaining about the high voltage and model order reduction combined application idea to expand more research points of view to reduce the complexity of high voltage design equipment.

TABLE III Comparision of parameters for the Original system with Reduced system

\begin{tabular}{|c|c|c|c|}
\hline S.NO & & $\begin{array}{c}\text { Original } \\
\text { system }\end{array}$ & $\begin{array}{c}\text { Reduced } \\
\text { system }\end{array}$ \\
\hline 1 & Peak & 1.0038 & 1.0032 \\
\hline 2 & Peak Time & $3.2011 \mathrm{e}-05$ & $3.2031 \mathrm{e}-05$ \\
\hline 3 & Settling Time & 0.0406 & 0.0401 \\
\hline 4 & Settling Max & 1.0038 & 1.0032 \\
\hline 5 & Settling Min & -0.5343 & -0.5622 \\
\hline 6 & Raise Time & $2625 \mathrm{e}-6$ & $2627 \mathrm{e}-6$ \\
\hline
\end{tabular}

\section{CONCLUSION}

The idea of this project is to estimate the amount of inductance causing the overshoot, and also to find which parameter is helpful to reduce that overshoot. when the inductance is present in the system of impulse generator. An optimization method has been done for the parameter calculation of the primary side winding of the transformer, to generate target switching impulse. The analysis has done in the basic fourth-order impulse circuits and wave shaping circuit parameters are obtained by using the optimization method [1-3]. By assuming the percentage overshoot the amount of inductance (L) is calculated. L for the overshoot is calculated, and the result is verified with the analytical expression. From the study, it is identified the limits of wave modulated inductance, which is causing the overshoot in the generation, are identified [4-6]. The calculated value of $\mathrm{L}$ through the optimization is compared with the simulation results. The data of circuit and impulse wave parameters corresponding to different overshoot is generated and the results are discussed. By changing one parameter and keep all remaining parameters constant, in the $4^{\text {th }}$ order circuit the value of R2 from $33 \mathrm{ohms}$ to $50 \mathrm{ohms}$ shown better results to reduce the wave modulated inductance effect and its peak voltage. In this paper an introduction is given for model order reduction, all the analysis is taken from the reference [16-19], in this numerator coefficients are found by using optimization method [18-19]. And denominator coefficients are found by using the stability equalization method. This method of model order reduction is giving better approximation for the original higher-order system.

\section{Acknowledgments}

The author wishes to acknowledge the valuable discussions with Chadaram Chandra Sekhar Junior Research Fellow in NIT Warangal, Author would also like to thank Assistant Professor Dr .K Chandrasekaran in NIT Raipur for their continuing interest and encouragement.

\section{REFERENCE}

[1] Matsumoto S. 2007, Analysis and evaluation of waveform parameters for oscillating impulse voltage. Transactions on Electrical and Electronic Engineering, IEEJ Transactions; 2(6):651-656.

[2] Matsumoto S. 2007Influence of the residual inductance of the impulse generator for the generation of the lightning impulse voltage. IEEJ Transaction on Power and Energy; 127(11):1213-1218.

[3] High-voltage test techniques Part 12007. General definitions and test requirements IEC 60060-1 Ed.3.

[4] Sato S, Harada T, Ebana T, Hoshi H, Sakaguchi S. Automatic2006; determination of the circuit constants fulfilling the given impulse time parameters. IEEJ Transactions on Fundamentals and Materials 126(9):887894.IEEJ.

[5] Hallstrom J, Berlijn S, Gamlin M, Garnacho F, Gockenbach E, Kato T, Li Y, Rungis J. 2005;Applicability of different implementations of Kfactor filtering schemes for the revision of IEC60060-1 and 2. In International Symposium on High Voltage Engineering, Beijing, China, Paper No.B-32,1-6. 
[6] Al-Suhail, M.; Meijer, S.; Smit, J.J.; Sibbald, P.; Kanters, J. October 2010, Analysis of diagnostic methods to prevent failure of critical GIS components. In Proceedings of the 2010 International Conference on High Voltage Engineering and Application (ICHVE), New Orleans, LA, USA, 11-14; pp. 220-223.

[7] Ren, M.; Dong, M.; Liu, Y.; Miao, J.; Qiu, A. 2014, Partial discharges in SF6 gas-filled void under standard oscillating lightning and switching impulses in uniform and non-uniform background fields. IEEE Trans. Dielectr.Electr. Insul. , 21, 138-148.

[8] Li, J.; Zhang, L.; Liang, J.; Yao, 2013, X. Partial discharge characteristics over SF6/epoxy interfaces under impulse voltage. IEEE Trans. Dielectr. Electr. Insul. , 20, 2158-2164.

[9] Okabe, S.; Tsuboi, T.; Takami, J. 2009, Basic study of possible waveforms generated in lightning impulse withstand voltage test on UHV equipment. IEEE Trans. Dielectr. Electr. Insul. 16, 1127-1133.

[10] Rozga, P. Streamer 2016, propagation and breakdown in a very small point-insulating plate gap in mineral oil and ester liquids at positive lightning impulse voltage. Energies, 9, 467.

[11] Siew, W.; Howat, S.; Chalmers, I. 1996, Radiated interference from a high voltage impulse generator. IEEE Trans. Electromagn. Compact. 38, 600-604.

[12] Del Vecchio, R.M.; Ahuja, R.; Frenette, R.D. 2002 Determining ideal impulse generator settings from a generator-transformer circuit model. IEEE Trans. Power Deliv., 17, 142-148.

[13] Ling, Y.; Chen, M. 2005, Calculation Method Tutorial; Xi'an Jiaotong University Press: Xi'an, China,.

[14] Y. Shamash, 1965,"Stable reduced-order models using Pad\&-type approximations," IEEE Trans. Automat. Contr. (Tech. notes and. J. Schwarz and B. Friedland, Linear Systems. NewYork: McGraw-Hill.

[15] G. Parmar, S. Mukherjee, and R. Prasad, 2007, System reduction using factor division algorithm and eigen spectrum analysis, Int. J.Applied Math. Modeling, Vol. 31, pp. 2542-2552,

[16] Lucas T.N., 1980, Factor division: A useful algorithm in model reduction Proc. Pt.D Vol. 130, No. 6, pp. 362364.

[17] A.K. Sinha, J. Pal, 1990 Simulation-based reduced-order modeling using clustering technique, Computer and Electrical Engineering., 16(3), 159-169.

[18] C. C. Sekhar, P. Singh, and P. D. Dewangan, 2020, "Model Order Reduction of Fixed Coefficient System with and without PID controller," 2020 First International Conference on Power, Control and Computing Technologies (ICPC2T), Raipur, India, pp. 102-105, DOI: 10.1109/ICPC2T48082.2020.9071456.
[19] S. Janardhanan, 2005,"Model Order Reduction and Controller Design Techniques". 